his profession.' If this ideal is now plainly impracticable, Dr. Newman reminds the educational theorists that, even in this field, an experiment is worthless if it can produce no discernible answer.

\section{NEW AND NONOFFICIAL REMEDIES, 1957}

Pp. 582. Philadelphia: J. B. Lippincott Co.; London: Pitman Medical Publishing Co. Ltd. 3os.

This year's edition of N.N.R. contains 42 new monographs, essentially 38 new substances being described. These include Acetazolamide, Meprobramate, Poliomyelitis vaccine, Promethazine Hydrochloride, and Phenoxymethyl Penicillin. Those familiar with previous editions will know the very high standard that is maintained in this one. Others will find these annual volumes a mine of authoritative, practical and very up-to-date information. The arrangement is convenient, and so devised that each book in itself forms a reference manual of practical therapeutics (for example, "Agents used in Allergy," "Analgesics," "Depressants and Stimulants," "Diuretics," and "Skeletal Muscle Relaxants" are a few of the admirably compressed monographs). Thirty shillings is very little to have to pay for 570 pages of closely-written information classified in this way and followed by a very complete index.

\section{AN INTRODUCTION TO PSYCHOPATHOLOGY}

By D. Russell Davis, M.R.C.S., M.R.C.P., M.B.B.Ch., M.D. Pp. vii +388 . London: Oxford University Press. 1957. 30s.

A book on psychopathology is a very rara avis indeed. Of books on psychiatry we have a surfeit, and our choice is by no means limited in books on abnormal psychology; these are not the same thing, however much confusion exists about these subjects. Psychiatrists write from the medical standpoint for the doctor who has to treat the patients described by the text-book, psychologists write in order to highlight psychological theories by reflecting abnormal states as exaggerations of the normal. Both approaches have their uses, but neither helps in bringing about a fusion of concept and theory. Like the underground railway and the pedestrian highway, they both serve the same area but only meet at isolated points. Dr. Russell Davis is one of the few men today whose grasp is wide enough to encompass both levels and provide such a comprehensive overview in one volume.

In two parts, the book deals with development and disorders. After an introductory chapter, and a survey of psycho-analysis, the author deals with aetiology, ecology, genetic and environmental factors, intellectual and emotional development, and developmental disorders. Part II covers experimental neurosis, applications of behaviour theory, mental disorder, organic states, and psychotherapy.
The list of contents alone indicates the author's bias towards psycho-dynamic explanations, and Freudian hypotheses find their way into most chapters. Other schools of thought are allowed their say, however, and learning theory is given a fair hearing. Readers with physiological or neurological interests will feel that the book has a disbalance in their disfavour. Experimental neuroses, for example, with their psychological explanations, cover 12 pages, experimental psychoses, requiring a biochemical explanation, cover two. There are few references to ethological concepts, although this is a field of rapidly growing importance, and no mention is made of the work of Konrad Lorenz in this connection. Occasionally a striking example which would form an ideal illustration of the subject matter is overlooked, as, for instance, the concept of protophrenia in discussing acquired mental defect in infancy (p. 12I).

These criticisms are those of selection only, which must always be present in a personal and creative work. They do not detract from the obvious merits of the book, which will readily fertilize the seeds of " personal medicine" which Woodger and Balint have recently sown. It will prove an excellent text-book for D.P.M. students and should be read by all psychiatrists and clinical psychologists. The best book on the subject in print today, it is likely to remain a standard University text for a long time to come.

L.R.C.H.

\section{THE BRITISH ENCYCLOPAEDIA OF MEDICAI} PRACTICE

\section{Medical Progress and Cumulative Supplement, 1956}

Edited by Sir Henry Cohen, M.D., D.Sc., LL.D., F.R.C.P., F.F.R. Second edition. Pp. xiv +364 , index pp. 14. London: Butterworth \& Co. Ltd. 1956.

The medical profession as a whole, and readers of the 'Encyclopaedia of Medical Practice' in particular, will have regretted the passing of Lord Horder, generally regarded as the most outstanding clinician of his time. Under his editorship the tremendous task of piloting the encyclopaedia through its second edition was completed and the new work is a landmark not only in a brilliant career, but also in medical publication.

No more appropriate choice of a successor to the editorship could have been made than Lord Cohen, whose reputation as a clinician and a diagnostician is no less brilliant than that of his predecessor's. Although the foreword of the current edition of 'Medical Progress' has been written by the new editor, the choice of subjects for discussion was Lord Horder's. This reflects, as always, as wise a catholic selection.

Part I consists of critical surveys in general medicine and surgery and in their principal specialities. The section on medicine and the law by the acknowledged expert, Dr. Robert Forbes, 